\title{
The Forest-Water Nexus: An International Perspective
}

\author{
Elaine Springgay ${ }^{1, *}$, Sara Casallas Ramirez ${ }^{1}$, Sally Janzen ${ }^{1,2}$ and Vitor Vannozzi Brito ${ }^{1,3}$ \\ 1 Food and Agriculture Organization of the United Nations (FAO), 00153 Rome, Italy; \\ Sara.CasallasRamirez@fao.org (S.C.R.); sally.janzen@fao.org (S.J.); vitor.brito@fao.org (V.V.B.) \\ 2 Environment and Human Security (UNU-EHS), United Nations University, D-53113 Bonn, Germany \\ 3 Department of Forest Sciences, Luiz de Queiroz College of Agriculture, University of São \\ Paulo (ESALQ-USP), Sao Paulo CEP 13418-900, Brazil \\ * Correspondence: elaine.springgay@fao.org
}

Received: 23 September 2019; Accepted: 15 October 2019; Published: 17 October 2019

\begin{abstract}
Discussions on the relationships between forests and water have primarily focused on the biophysical nature of these relationships. However, as issues such as land degradation affect the ability of forests to provide water-related ecosystem services resulting in water insecurity, the human dimension of the forest-water nexus has become more evident. This has resulted in the identification of the forest-water nexus as an issue that requires urgent recognition within major international policy processes and where knowledge gaps on the global state of the nexus exist. To address this, two major international policy frameworks driving the current development and environment agenda, namely the Sustainable Development Goals and the (Intended) Nationally Determined Contributions were analyzed to assess the integration of forests and water in international policy agenda. In addition, data on tree cover and water risks as well as data on forests managed for soil and water protection was analyzed to understand the global state of the forest-water nexus. The results indicate that even though there is no single indicator monitoring forest-water interactions, there are existing indictors that provide partial information on the forest-water nexus, which would be key to measuring progress towards the 2030 Agenda for Sustainable Development. Furthermore, the research has highlighted increasing political will as well as global trends that could be used to further harness support and include the forest-water nexus in these global policy agenda. As international processes move forward, the methodology presented here provides a way to evaluate progress of global management of forests for water ecosystem services and gives specific areas where further research that integrates the scientific and socio-political spheres is needed. It is hoped that the initial approach presented in this paper serves as a stepping-stone for further action that might result in better management of and policies for our global forest-water resources and their associated ecosystem services.
\end{abstract}

Keywords: forest and water policy; sustainability; climate change; forest hydrology; SDGs

\section{Introduction}

Forests and trees in the landscape are an integral component of the water cycle: regulating streamflow, fostering groundwater recharge and contributing to atmospheric water recycling, including cloud generation and precipitation downwind through the process of evapotranspiration [1]. They also act as natural filters, reducing soil erosion and water sedimentation, thus providing high quality water for human consumption, industry and the environment. These multitudes of water-related benefits that forests provide to society are referred to as water ecosystem services of forests, which are important for maintaining healthy ecosystems, landscapes and communities (Figure 1). In the international community - those engaged in international policy and development activities-the relationships between forests and water, and the resulting ecosystem services these relationships provide, are referred to collectively as the forest-water nexus, which can also be included with other 
sectors, such as energy or food, or broadened as the climate-forest-water-people nexus [2]. Appendix A includes the definitions of the forest-water nexus terminology used in this paper.

\begin{tabular}{|c|c|c|}
\hline \multicolumn{3}{|c|}{ Water Ecosystem Services from Forests } \\
\hline $\begin{array}{ll}\text { Provisioning Services } \\
\text { - } & \text { Food } \\
\text { - } & \text { Raw materials (fuel wood and } \\
& \text { fiber) } \\
\text { - } & \text { Freshwater } \\
\text { - } & \text { Medicinal resources } \\
\text { Supporting Services } \\
\text { - Habitat for species } \\
\text { - Maintenance of genetic } \\
\text { diversity } \\
\text { - Nutrient cycling } \\
\text { Soil formation }\end{array}$ & $\begin{array}{l}\text { Regulating Services } \\
\text { - } \quad \text { Local climate air quality } \\
\text { - } \quad \text { Carbor purification } \\
\text { - } \text { Modequestration and storage } \\
\text { - } \quad \text { Biological control } \\
\text { - } \quad \text { Erosion prevention and } \\
\text { - maintenance of soil fertility } \\
\text { - Pollination } \\
\text { Regulation of water flow }\end{array}$ & $\begin{array}{ll}\text { Cultural Services } \\
\text { - } & \text { Recreation and mental } \\
& \text { and physical health } \\
\text { - } & \text { Tourism } \\
\text { - } & \text { Aesthetic appreciation } \\
\text { and inspiration for } \\
\text { culture, art and design } \\
\text { - } & \text { Spiritual experience and } \\
& \text { sense of place }\end{array}$ \\
\hline
\end{tabular}

Figure 1. Water ecosystem services provided by forests. Adapted from Millenium Ecosystem Assessment (MEA) (2005) [3].

Until recently, the topic of the forest-water nexus has primarily been discussed within the research community focusing on the biophysical nature of forest-water relationships: the quantity and quality of water within and from forests, and how these change over time under different scenarios, including land-use and climate change and management regimes. However, the water ecosystem services from forests have come under increasing pressures from growing human population, contributing to tree cover loss, land conversion and degradation, and/or increasing demands for water, which are all exacerbated by climate change. This has highlighted the forest-water nexus as a human issue that requires urgent socio-political attention.

While there is increasing attention on the social aspects of an integrated approach to forests and water, this is generally limited to valuating water ecosystem services from forests. There is very little information on the socio-political impacts and implications of the forest-water nexus, and this is partly attributed to the contextual nature of forest-water interactions and that these relationships are dependent on scale [4]. In the past 20 years, according to Web of Science, only $0.4 \%$ of forest-water scientific articles (based on title) are related to policy and/or governance. Similarly, at a recent international Forest and Water Conference in 2018, of 139 presentations only four (3\%) were related to (international) policy, resulting in a conference recommendation to look at this area more closely in the future. Therefore, the lack of a science-policy-practice interface is a catch-22, where the forest-water nexus is not effectively mainstreamed in policy or practice, and where there is a lack of research in the socio-politics of forests and water. Moreover, many of these articles are on specific countries or regions, and do not effectively advocate for the importance of forest-water relationships at the global level, or for international agenda that could result in global policies implemented at country level as has been the case with many other environmental issues.

As a means of initiating these discussions, this paper will review how the forest-water nexus is recognized and represented in international frameworks and assess the global status of forests managed for water. The objective is to synthesize where the forest-water issue stands from an international political perspective, identify gaps and propose some recommendations on how an integrated approach to forests and water could be more effectively aligned to a broader international agenda.

To consider how the forest-water nexus is represented in the international agenda, a review of the Sustainable Development Goals (SDGs) and the (Intended) Nationally Determined Contributions ((I)NDCs) to the Paris Agreement of the United Nations Framework Convention on Climate Change (UNFCCC) will be presented. These were chosen as the SDGs are the umbrella framework driving the development and environment agenda and the Paris Agreement and its (I)NDCs are the main 
mechanism driving the environment and climate change agenda. Other frameworks are also important but undoubtedly, it is the SDGs and Paris Agreement that currently receive increasing support from decision makers and different sectors of society and drive global commitments. The status of forests managed for water globally will be determined by analyzing global trends in tree cover and how these changes correspond to water risk, specifically erosion, forest fires and water stress [5]; as well as looking at global data on forests managed for soil and water protection based on national reporting [6].

\section{Methodology}

In order to provide an overview of the international enabling environment for integrated forest-water management, an analysis of two major international policy instruments was conducted to determine the extent to which the forest-water nexus is included in commitments, as well as an analysis of two available global datasets to better understand a general global baseline of the forest-water nexus. Due to limitations in these global datasets, a biome-level comparison was not conducted; instead the paper focuses on the degree to which the forest-water nexus is recognized in international policies, and the global extent of forests in relation to water ecosystem services, as defined by the existing datasets.

\subsection{Forests and Water Within the International Political Agenda}

\subsubsection{Forests and Water within the 2030 Agenda for Sustainable Development}

A desk study was carried out to better understand the SDGs and the indicators that are applicable to the forest-water nexus, namely indicators 6.6.1, 15.1.1 and 15.1.2. The official methodologies for reporting on each of the indicators were also reviewed to identify possible data gaps with respect to the forest-water nexus. This information is publicly available on the UN Statistics Division Sustainable Development Goals Metadata Repository (available at: https://unstats.un.org/sdgs/metadata/). Due to the limitations of the methodologies and metadata, a more extensive analysis was not possible.

\subsubsection{Forests and Water in Climate Change}

A total of 168 (I)NDCs were reviewed for the recognition of the forest-water nexus. In order to evaluate the extent to which the integration of forest and water resource management was included in the (I)NDCs, a keyword search was conducted on all available (I)NDC reports as of March 2019 in the UNFCCC NDC registry [7] and the (I)NDC Submission Portal [8]. With the exception of (I)NDCs in Russian, all (I)NDCs were reviewed in their original language.

Reports were reviewed for the forest-water keywords listed in Table 1, as well as contextual keywords (and their respective equivalents/translations in French, Spanish and Arabic). These keywords were chosen for their relevance to the forest-water nexus and their definitions are available in Annex 1. Analysis for the forest-water nexus was conducted using both a keyword search and a qualitative assessment of the context for which the keywords were referenced. If a country made reference to the forest-water nexus, they were given a 1 , and if not, a 0 . The number of countries recognizing forest-water relationships within their (I)NDCs were then counted.

Additionally, a record was made when (I)NDCs recognized water-related services provided by forest and when (I)NDCs explicitly referred to forests and water in an integrated manner. For example, "The forests and gardens... are of critical importance for the preservation of mountain ecosystems and biodiversity, improvement of the state of lands and prevention of their further degradation, protection of vulnerable infrastructure, protection of water resources and carbon absorption from the atmosphere" was considered a reference to the water-related ecosystem services provided by forests. Similarly, examples of the integration of forest-water management include "[ ... ] enhance the protection and restoration of forest ecosystems and build the resiliency of water catchment areas"; and references to "Promote the protection of catchment forests in... watersheds" within the context of protecting and conserving water. 
Table 1. List of keywords used in the (Intended) Nationally Determined Contributions ((I)NDCs) review.

\begin{tabular}{lllll}
\hline & \multicolumn{2}{c}{ Forest-Water Keywords } & & Contextual Keywords \\
\hline - Ecosystem service; & $\bullet$ & Riparian; & $\bullet$ & Adaptation; \\
- Integrated; & $\bullet$ & Swamp; & $\bullet$ & Forest; \\
- Mangrove; & $\bullet$ & Watershed; & $\bullet$ & Mitigation; \\
- Rainforest; & $\bullet$ & Wetland. & $\bullet$ & Water. \\
\hline
\end{tabular}

\subsection{Analysis of Global Forest-Water Datasets}

\subsubsection{Tree Cover and Water Risk}

A global-level analysis of the World Resources Institute (WRI) Global Forest Watch Water data, which includes geospatial tree cover data from Hansen et al. (2013) [9] by major global watershed, or hydroshed, as defined by the Food and Agriculture Organization (FAO) of the United Nations (UN) (2011) [10], as well as data from WRI's Aqueduct water risk mapping tool, was conducted to identify possible trends between estimated tree cover loss and water-related risks. Only data provided and defined by WRI (see Qin et al., 2016 [11] for further information on definitions, data sets used and analysis) was calculated to observe changes in proportional tree cover, which was in turn compared to WRI-provided data on water-related risks, namely erosion, forest fires and baseline water stress. It was recognized that the data had limitations (e.g., it does not take into account different forest or soil types, and provides a classification score for the entire hydroshed).

For reference, the indicator of erosion was derived from the modeled erosion potential based on the revised universal soil loss equation (RUSLE) model [12], which uses average annual precipitation, elevation, slope, soil properties and land cover to predict annual soil loss from rainfall and runoff. To calculate risks of fire, Qin et al. (2016) [11] used the fire occurrence as data input, averaging annual fire occurrence per million hectares in a watershed to account for seasonality and El Niño/La Niña events. After calculation, the indicators on erosion and fire risks were normalized and categorized into five quantiles, assigning a score from 1 to 5 . For baseline water stress risk, the ratio of total water withdrawals relative to the annual available renewable surface water supplies was calculated averaging monthly values. Scores were assigned for each basin, based on the raw value: $<10 \%$ : low; 10\%-20\%: low-medium; $20 \%-40 \%$ : medium-high; $40 \%-80 \%$ : high and $>80 \%$ : extremely high [13].

The proportion of tree cover area by hydroshed was calculated as a ratio of tree cover within the watershed, and total watershed area; this ratio was calculated for historic tree cover (estimated pre-2000 tree cover as calculated and provided by WRI), 2000 and 2015. Changes in tree cover, were calculated as the difference between historic tree cover and tree cover in 2000 and 2015. Ultimately, the estimated total proportional tree cover loss between historic and 2015 tree covers was used to compare to the risks identified by WRI.

Global Forest Watch Water already designated risk data based on scores 1-5 (1 being the lowest risk and 5 being the highest) for each watershed for erosion and fire. Baseline water stress data was presented visually by WRI using a map with a colored classification system. To align with the other risks, a 1-5 score was assigned for each watershed based on a visual analysis to determine the average risk. This analysis was conducted independently by two individuals and then compared. Most scores were in agreement. In the event two scores differed, the baseline water stress data was re-evaluated and a score was assigned based on agreement between the two evaluators.

To determine if there was potential correlation between tree cover loss and risks, the hydrosheds were then organized by proportional tree cover loss and risk score, then counted. Based on the distribution of the data, the percentage of watersheds with medium high, high and very high risks were calculated for the different categories of estimated proportional tree loss (Table 2), and an average calculated for watersheds that experienced greater than $50 \%$ estimated tree loss. 
Table 2. Distribution of watersheds by estimated tree cover loss (up to 2015) and erosion risk.

\begin{tabular}{ccccccc}
\hline Risk/\% Tree Loss & $\mathbf{1}$ & $\mathbf{2}$ & $\mathbf{3}$ & $\mathbf{4}$ & $\mathbf{5}$ & Total \\
\hline$<10 \%$ & 10 & 18 & 12 & 3 & 7 & 50 \\
$10 \%-20 \%$ & 6 & 6 & 3 & 2 & 1 & 18 \\
$20 \%-30 \%$ & 15 & 7 & 3 & 4 & 3 & 32 \\
$30 \%-40 \%$ & 7 & 5 & 4 & 6 & 5 & 27 \\
$40 \%-40 \%$ & 4 & 3 & 2 & 3 & 5 & 17 \\
$50 \%-60 \%$ & 0 & 1 & 9 & 8 & 8 & 26 \\
$60 \%-70 \%$ & 1 & 4 & 6 & 5 & 4 & 20 \\
$70 \%-80 \%$ & 1 & 1 & 2 & 9 & 2 & 15 \\
$80 \%-90 \%$ & 0 & 1 & 4 & 3 & 6 & 14 \\
$>90 \%$ & 0 & 1 & 2 & 1 & 7 & 11 \\
Total Watersheds & 44 & 47 & 47 & 44 & 48 & 230 \\
\hline
\end{tabular}

\subsubsection{Forests Managed for Soil and/or Water Protection}

FAO's Global Forest Resources Assessments (FRA) data [6] includes the extent of forests managed for the protection of soil and/or water as reported by country. For each country, the proportion of forest with the protection of soil and water as a main management objective was calculated in relation to the total forested area in the country. A similar analysis was also conducted for the main regions of the world (North America, South America, Africa, Asia, Europe and Oceania). Likewise, a more detailed analysis was carried out to report on the percentage of national forests that are managed for the following specific management objectives: coastal stabilization, clean water, erosion, avalanche and desertification control. The results were expressed as a percentage of the total forested area in the country, and then calculated at regional level. It is acknowledged that there are limitations to FRA data, namely it relies on country self-reporting, is limited to extent area and does not account for where forests managed for water, or how effective this management is; however, it is one of the only global datasets available and has 25 years of national data.

\section{Results}

\subsection{Forests and Water Within the International Policy Agenda}

\subsubsection{Sustainable Development Goals}

The interconnection between forests and water is explicitly referenced in two SDGs: to achieve clean water and sanitation (SDG 6) and to maintain life on land (SDG 15). In target 6.6, forests are recognized as water-related ecosystems; similarly, target 15.1 refers to forests as freshwater ecosystems (Figure 2). Within these targets, the most relevant indicators are 6.6.1 and 15.1.1. Unfortunately, neither specifically measure the interrelationship between forests, or landscape management and water [14]. The analysis done within the context of this paper allowed for a better understanding of the indicators and highlights specific knowledge gaps, especially when it came to harnessing the current political momentum and leveraging support for targeted actions.
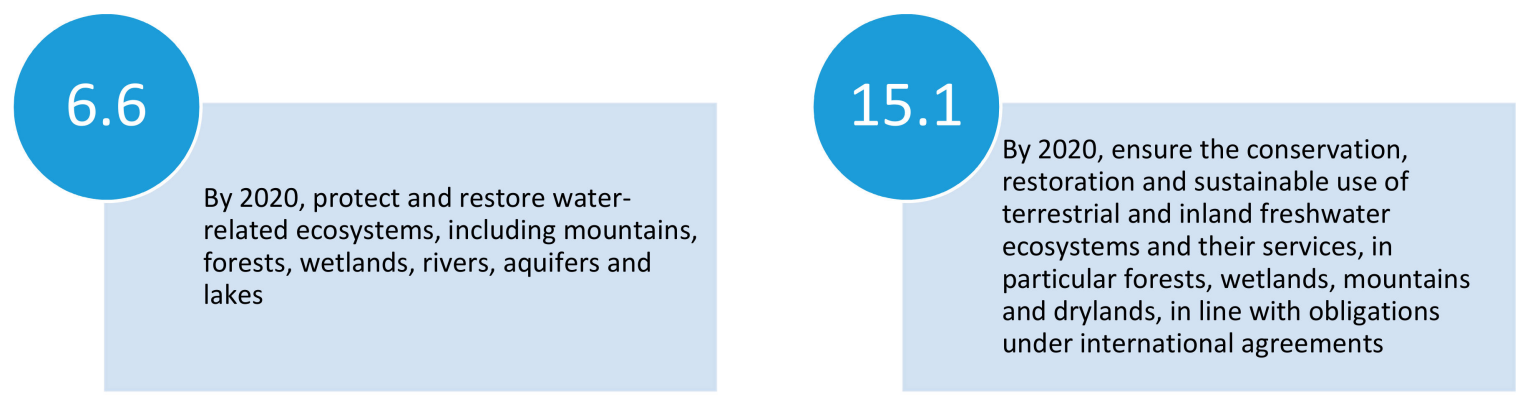

Figure 2. Sustainable Development Goal (SDG) targets related to forests and water. 
SDG indicator 6.6.1, which measures the "Change in the extent of water-related ecosystems over time" has two approved methodologies for measuring it. These methodologies were provided by the UN Environment and the Ramsar Convention Secretariat. Both address forested water-related ecosystems to a certain extent but the main concern is that the indicator measures spatial extent but does not consider the spatial distribution of these ecosystems. It does not take into account whether these ecosystems occur in upland or lowland areas, effectively provide water-related ecosystem services or are accessible to communities.

Like SDG target 6.6, SDG target 15.1 also addresses only certain ecosystems, does not consider effectiveness and relies on country self-reporting. Target 15.1 has two indicators 15.1.1 and 15.1.2 that measure "forest areas as a proportion of total land area" and the "proportion of important sites for terrestrial and freshwater biodiversity that are covered by protected areas, by ecosystem type", respectively. The former focuses only on forest ecosystems and measures total forest extent by country; and the latter focuses on protected areas for (terrestrial and freshwater) biodiversity, and does not consider other ecosystem functions or services [14]. Moreover, neither of the indicators disaggregate for different forest ecosystem types [15].

\subsubsection{Forests and Water in Climate Change}

Of the 168 (I)NDCs available during the analysis, 45 percent made reference to keywords associated with the forest-water nexus (see Figure 3 below). Most (I)NDCs including forest-water keywords report on integrated (water) resource management and mangrove forests (Table 3). North and Central America had the highest percentage of (I)NDCs that include the forest-water nexus, primarily due to references related to Integrated Resource Management (IRM)/ Integrated Water Resources management (IWRM) and mangroves, followed closely by Africa and South America. Europe, Canada and the USA did not make any references to the forest-water nexus in the (I)NDCs, which was surprising considering these regions manage a high percentage of their forests for water, which will be further discussed $[14,16]$.

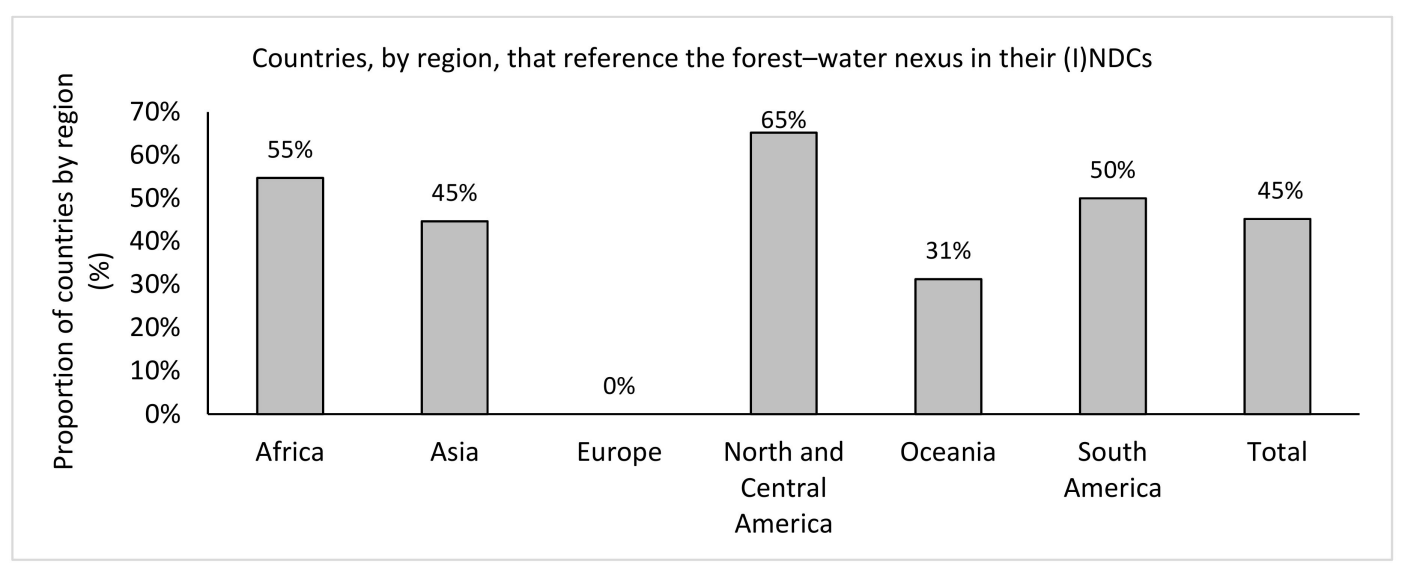

Figure 3. Proportion of countries by region that reference the forest-water nexus in their (I)NDCs.

Table 3. Proportion of (I)NDC keywords related to the forest-water nexus by region.

\begin{tabular}{cccccccc}
\hline FAO Region/ Keyword & Africa & Asia & Europe & North and Central America & Oceania & South America & GLOBAL \\
\hline Mangrove & $17 \%$ & $19 \%$ & - & $43 \%$ & $19 \%$ & $17 \%$ & $20 \%$ \\
Swamp Forest & - & $4 \%$ & - & - & - & - & $1 \%$ \\
Rainforest & $2 \%$ & $2 \%$ & - & - & - & $8 \%$ & $2 \%$ \\
Wetland & $11 \%$ & $6 \%$ & - & $17 \%$ & - & - & $9 \%$ \\
Riparian & $2 \%$ & $4 \%$ & - & $9 \%$ & $17 \%$ & $42 \%$ & $34 \%$ \\
IRM & $49 \%$ & $30 \%$ & - & $43 \%$ & $13 \%$ \\
\hline
\end{tabular}


Thirty-three percent of (I)NDCs globally acknowledged water ecosystem services of forests and 25 percent include integrated forest-water management (Table 4). Interestingly, the recognition of water ecosystem services provided by forests was higher than the mention of integrated forest-water management in all the regions, with exception of Oceania.

Table 4. Share of (I)NDCs reporting on water-related services provided by forests and integrated forest water management per FAO region.

\begin{tabular}{cccccccc}
\hline $\begin{array}{c}\text { FAO Region/Forest-Water } \\
\text { Context }\end{array}$ & Africa & Asia & Europe & $\begin{array}{c}\text { North and } \\
\text { Central America }\end{array}$ & Oceania & $\begin{array}{c}\text { South } \\
\text { America }\end{array}$ & Global \\
\hline $\begin{array}{c}\text { Water ecosystem services } \\
\text { provided by forests }\end{array}$ & $36 \%$ & $34 \%$ & $6 \%$ & $43 \%$ & $13 \%$ & $67 \%$ & $33 \%$ \\
\hline $\begin{array}{c}\text { Integrated forest and } \\
\text { water management }\end{array}$ & $34 \%$ & $21 \%$ & $0 \%$ & $35 \%$ & $13 \%$ & $33 \%$ & $25 \%$ \\
\hline
\end{tabular}

\subsection{Analysis of Global Forest-Water Datasets}

\subsubsection{Tree Cover and Water Risk}

At the global scale, the world can be divided into 230 major watersheds, or hydrosheds [10]. According to WRI Global Forest Watch Water data, it was estimated that these hydrosheds historically (pre-2000) averaged approximately 68 percent tree cover. By 2000, average tree cover was reduced to 31 percent, and by 2015 had further reduced to an average of 29 percent. Approximately 38 percent of these hydrosheds had lost more than half of their tree cover prior to 2000, with this number increasing to 40 percent by 2015 .

Decreases in tree cover and forest condition could result in increased soil erosion and degradation (Figure 4), which in turn might lead to reduced water quantity and quality. Loss of tree cover generally results in short-term increases in water yield; however, in some cases loss of tree cover can be associated with reduced water availability in the long-term, especially when natural forest is converted to other land uses that degrade and/or compact soils, thus reducing soil infiltration, water storage capacity and groundwater recharge $[1,14,17]$. In addition, the risk of hazards, such as floods, forest fires, landslides and storm surge, increases together with potential impacts [11,14].

The global WRI (2017) [5] data appeared to support this, showing that amongst the hydrosheds that experienced greater than 50 percent tree cover loss by 2015, 88 percent had a medium to very high risk of erosion, 68 percent had a medium to very high risk of forest fire and 48 percent had a medium to very high risk of baseline water stress (Figure 4). 

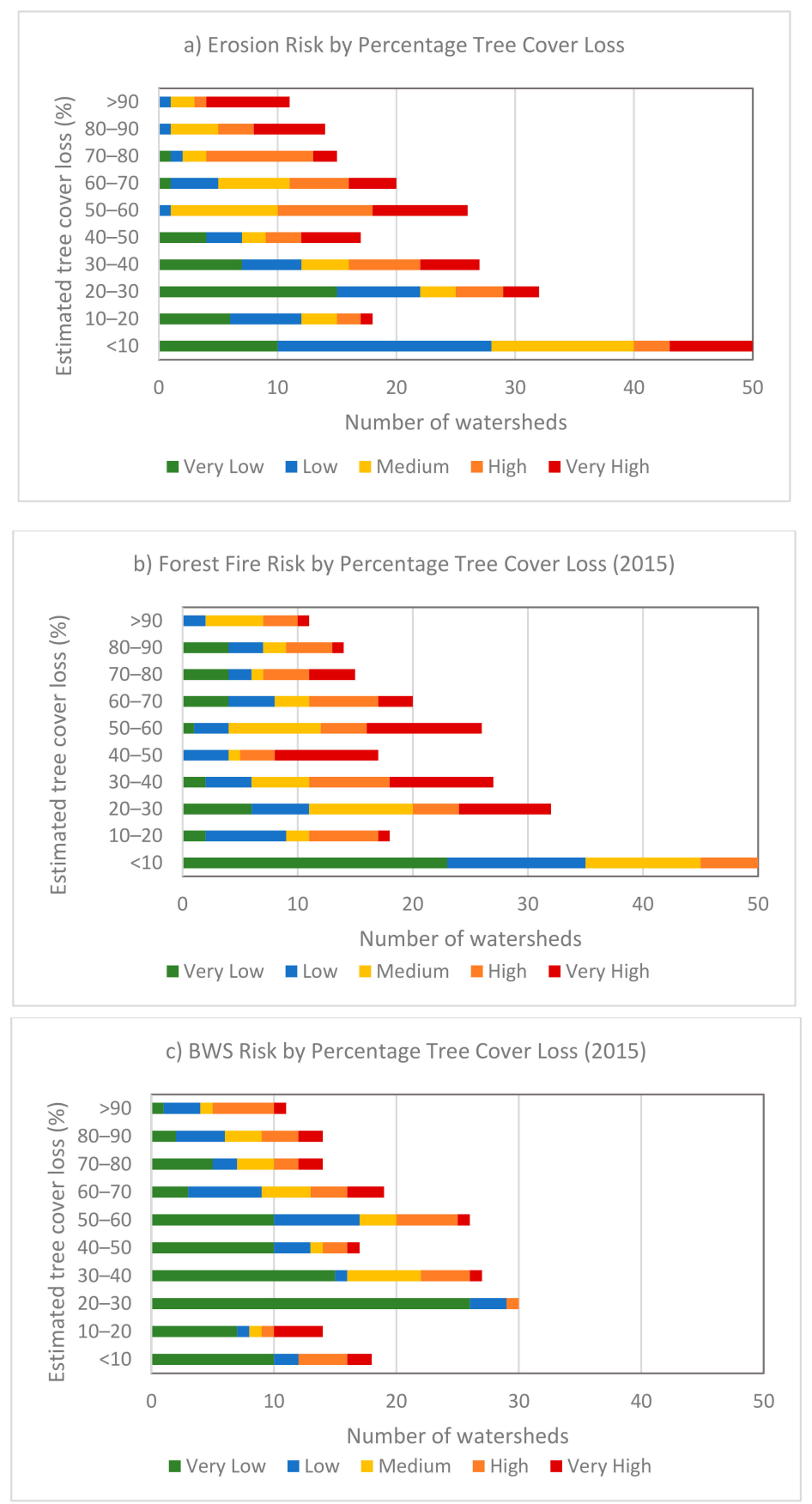

Figure 4. Potential relationship between (a) tree loss and erosion risk, (b) forest fires and (c) baseline water stress (BWS). Data sourced from WRI (2017) [5].

\subsubsection{Forests Managed for Soil and/or Water Conservation}

Based on data reported in FAO's FRA [6], forests managed for soil and water protection had increased globally over the past 25 years (Figure 5c), with most regions reporting a positive trend in protecting forests for soil and water, with the exception of Africa and South America. Yet as of 2015, only 25 percent of forests globally were managed with soil and water protection as one of the primary objectives (Figure 5a). In addition, approximately 10 percent of forests were primarily managed for soil and/or water, including almost 2 percent managed primarily for clean water and about 1 percent for each coastal stabilization and soil erosion control. If considering only the global south, i.e., Africa, Asia-Pacific and South America, the average extent of forests managed for soil and water protection reduced to less than 17 percent of total forest area. 


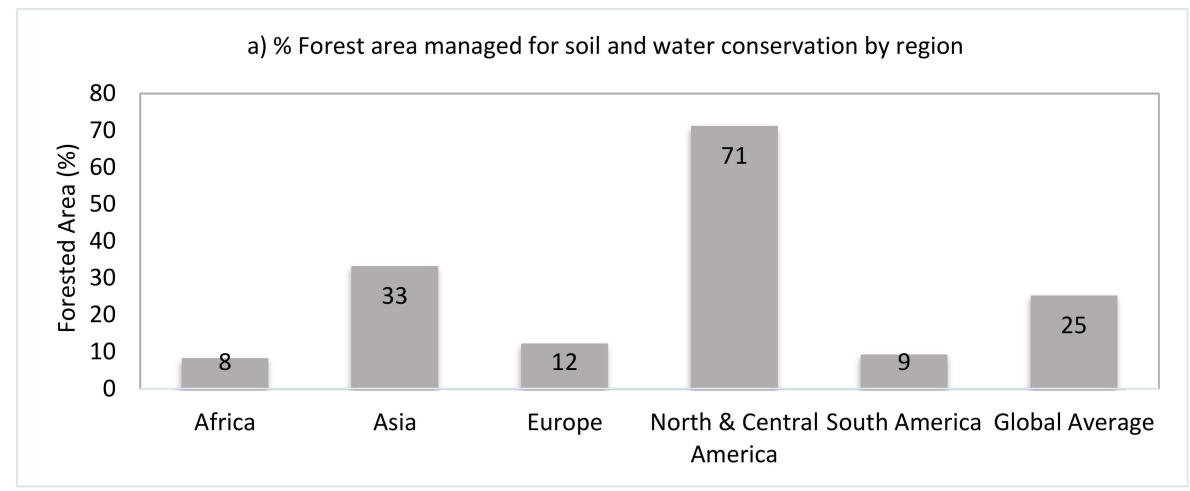

b) \% Forest area managed for soil and water conservation by country

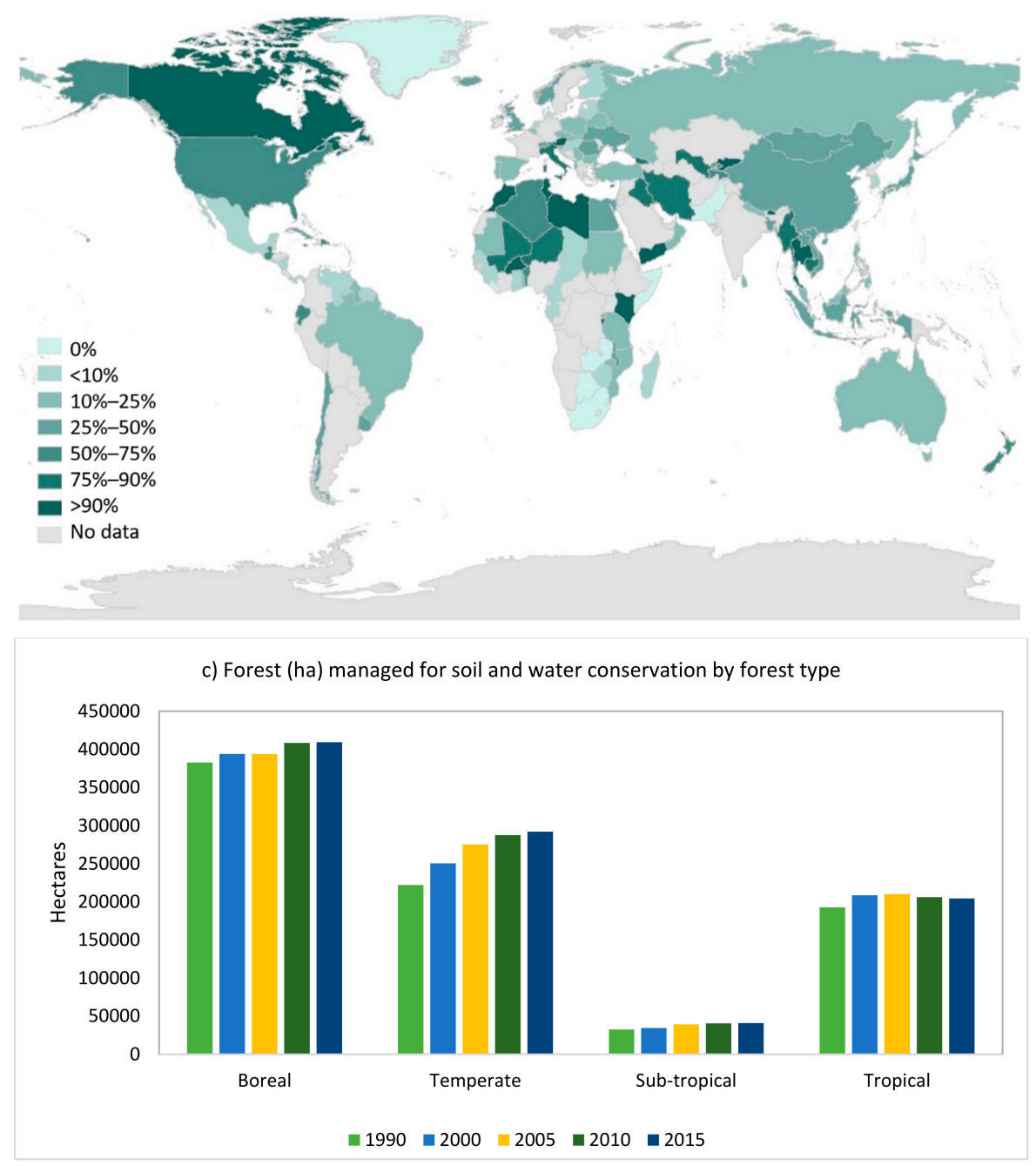

Figure 5. (a) Percentage area of forests for soil and water protection by region; (b) percentage area of forests for soil and water conservation by country, shown graphically, and, (c) number of hectares of forests for soil and water protection by forest type. Data sourced from FAO (2015) [6].

The discrepancy between global north and global south correlated with data by forest type, where boreal and temperate forests had seen a steady upward trend, whereas sub-tropical and tropical forests had seen decreases in forests managed for soil and water protection due to recent forest loss.

While the global average was low, many sub-regions reported that around 30 percent or more of their forests were managed for the protection of soil and water, including the Caribbean, North America, 
Northern Africa, South and Southeast Asia and Western and Central Asia. Over 70 percent of forests in North America were managed with considerations for soil and water protection; most communities depend on forested watersheds for their high-quality water supply, and the US Forestry Service identifies itself as the manager of the largest national water resource [18]. Interestingly, Europe fell below the global average of managing forests for soil and water protection because most forest land was privately owned and was not accounted for in national reporting; however, the recent FAO and UNECE report on "Forests and Water: Valuation and payments for forest ecosystem services" [16] provides ample evidence that an integrated approach to forest-water management occurs at regional and national levels.

Thirteen countries also reported in FRA 2015 that 100 percent of their forests are managed with soil and water protection as a main objective: Austria, Bhutan, Isle of Man, Jamaica, Kenya, Kyrgyzstan, Libya, Martinique, Mayotte, Morocco, Saint Pierre and Miquelon, Tunisia and Yemen. All of these countries are areas vulnerable to shocks, either island nations, mountainous and/or dryland areas. In addition to regulating water supply, these forests likely act as natural infrastructure for natural disasters and/or to maintain high quality water supply [14].

The FRA 2015 also provides data that a number of countries have forest areas that are primarily managed for clean water, erosion control, desertification control, coastal stabilization and/or avalanche control; these were summarized in FAO's State of the World's Forests 2018 (see Table 5). For example, 7 percent of Austria's forests were managed primarily for clean water and another 30 percent were managed primarily for erosion control. For each category, the top countries were listed by percentage of total forest area, with the exception of avalanche control, which was only reported by Tajikistan and Switzerland at 14 and 7 percent, respectively. 
Table 5. Top countries with soil and/or water protection as a primary management objective. Source: FAO 2015 and FAO 2018.

\begin{tabular}{|c|c|c|c|c|c|c|c|}
\hline Clean Water & Forest Area(\%) & Erosion Control & Forest Area(\%) & Desertification Control & Forest Area(\%) & Coastal Stabilization & Forest Area(\%) \\
\hline Japan & $36.7 \%$ & Timor-Leste & $32.4 \%$ & Uzbekistan & $80.3 \%$ & Cuba & $18.3 \%$ \\
\hline Guadeloupe & $25.1 \%$ & Austria & $29.8 \%$ & Iceland & $34.8 \%$ & Lithuania & $8.0 \%$ \\
\hline Uruguay & $19.8 \%$ & Switzerland & $27.5 \%$ & Mauritania & $17.4 \%$ & Bangladesh & $4.3 \%$ \\
\hline Mauritius & $14.8 \%$ & Ukraine & $25.2 \%$ & Mauritius & $17.4 \%$ & Ukraine & $3.5 \%$ \\
\hline Bangladesh & $13.5 \%$ & Tajikistan & $25.0 \%$ & Oman & $15.0 \%$ & Belarus & $3.4 \%$ \\
\hline Tonga & $11.1 \%$ & Romania & $20.4 \%$ & Sudan & $13.0 \%$ & Guadeloupe & $3.0 \%$ \\
\hline Romania & $10.6 \%$ & Guadeloupe & $17.3 \%$ & Tajikistan & $12.1 \%$ & Russia & $3.0 \%$ \\
\hline Slovenia & $10.5 \%$ & Serbia & $17.1 \%$ & Bangladesh & $2.4 \%$ & Jamaica & $2.8 \%$ \\
\hline Sierra Leone & $9.4 \%$ & Slovakia & $16.9 \%$ & Serbia & $1.2 \%$ & Malaysia & $1.5 \%$ \\
\hline Malaysia & $9.0 \%$ & Turkey & $13.9 \%$ & Chad & $0.4 \%$ & Portugal & $1.4 \%$ \\
\hline
\end{tabular}




\section{Discussion}

\subsection{The Forest-Water Nexus Is a Human Well-Being Issue}

Human wellbeing is intrinsically related to the ability of nature to provide ecosystem services. In terms of the forest-water nexus, the contribution of loss of tree cover and land degradation to water insecurity further emphasizes the human dimension of the nexus and the need to work together across the scientific and socio-political spheres. The United Nations University UNU (2013) [19] explained water security as "the capacity of a population to safeguard sustainable access to adequate quantities of acceptable quality water for sustaining livelihoods, human wellbeing and socio-economic development, for ensuring protection against water-borne pollution and water-related disasters, and for preserving ecosystems in a climate of peace and political stability". According to estimates, human demands for water, energy and food production are expected to increase by $30-50$ percent, which accompanied with a business-as-usual climate scenario, is projected to result in a 40 percent global water deficit by $2030[20,21]$. This is alarming when considering that 80 percent of the world's population already suffers from water insecurity [22]. The sustainable management of forests and landscapes with trees play a key role in mitigating the negative trends in water security and as such, their ability to deliver water ecosystem services must be central to management objectives.

Forest and water interactions are complex making management of forests to address water insecurity even more important. For instance, forests and trees use water-particularly in earlier stages of growth. Large-scale restoration commitments to return forests to the landscape for their goods and services will also alter hydrology. For example, Bastin et al. (2019) [23] estimate that 0.9 billion hectares of trees can be restored globally, representing more than 25 percent increase in forested area-what will this mean for water resources under pressure from growing human populations? Selecting the right species, growing them in the right place and implementing the right forest management regime will be crucial to managing trade-offs [4].

The importance of the forests and water to address human well-being is one of the reasons why they are recognized in the Sustainable Development Goals. However, the data presented show that while forests are increasingly being recognized for their water ecosystem services at international and national levels, this recognition is relatively tokenistic: Countries have not committed resources to addressing integrated forest-water management on the ground, and current methodologies are limited in how they measure targeted progress.

\subsection{International Momentum}

The forest-water nexus has been gaining international attention over the past two decades. The 2002 Shiga Declaration on Forests and Water provided one of the first frameworks for action. At this meeting, over 100 forest and watershed management experts from around the world and 16 international organizations and Non-governmental organizations (NGOs) met to discuss the state of forests and water knowledge at the time and provided recommendations to better understand the ecosystem services provided by forests. Since then, over twenty major international conferences on forests, water and climate change have discussed and advocated for the importance of managing for forest-water relationships; many of these events and their recommendations were summarized in Forests and Water: International Momentum and Action [24].

Due to the forest-water nexus being a relevant cross-cutting issue for international development objectives and the resulting growing momentum in discourse, it is recognized in many international agenda (Figure 6), and in recent years has received more explicit mention. Since 2015, there has been an emphasis to address the recommendations of improving awareness and understanding of forest-water relationships, and linking science, policy and practice. As a result, there has been an increase in advocacy strategically aimed at influencing international processes, and a number of publications have emerged to summarize decades-worth of forest-water research and practice, as well as the implications and contributions of the forest-water nexus to achieving international objectives and 
priorities, including goals related to sustainability, climate change, forest and landscape restoration (FLR), biodiversity, and water scarcity. For example, Ellison et al. (2017) [1] provided a scientific review of how forest-water relationships contribute to climate change, which was promoted at the UNFCCC Conference of the Parties (COP) 21 and 22; the Global Forestry Expert Panel produced a synopsis of forest-water scientific understanding and policy recommendations [2], which was launched at the High Level Political Forum on Sustainable Development for SDGs 6 and 15, and presented to the Commission on Forestry in 2018; and a group of forest and water experts provided policy recommendations for the forest-water nexus in climate change and FLR [4,25], at the World Water Forum in Brazil in 2018, as well as the UNFCCC Talanoa Dialogue process for COP 24.

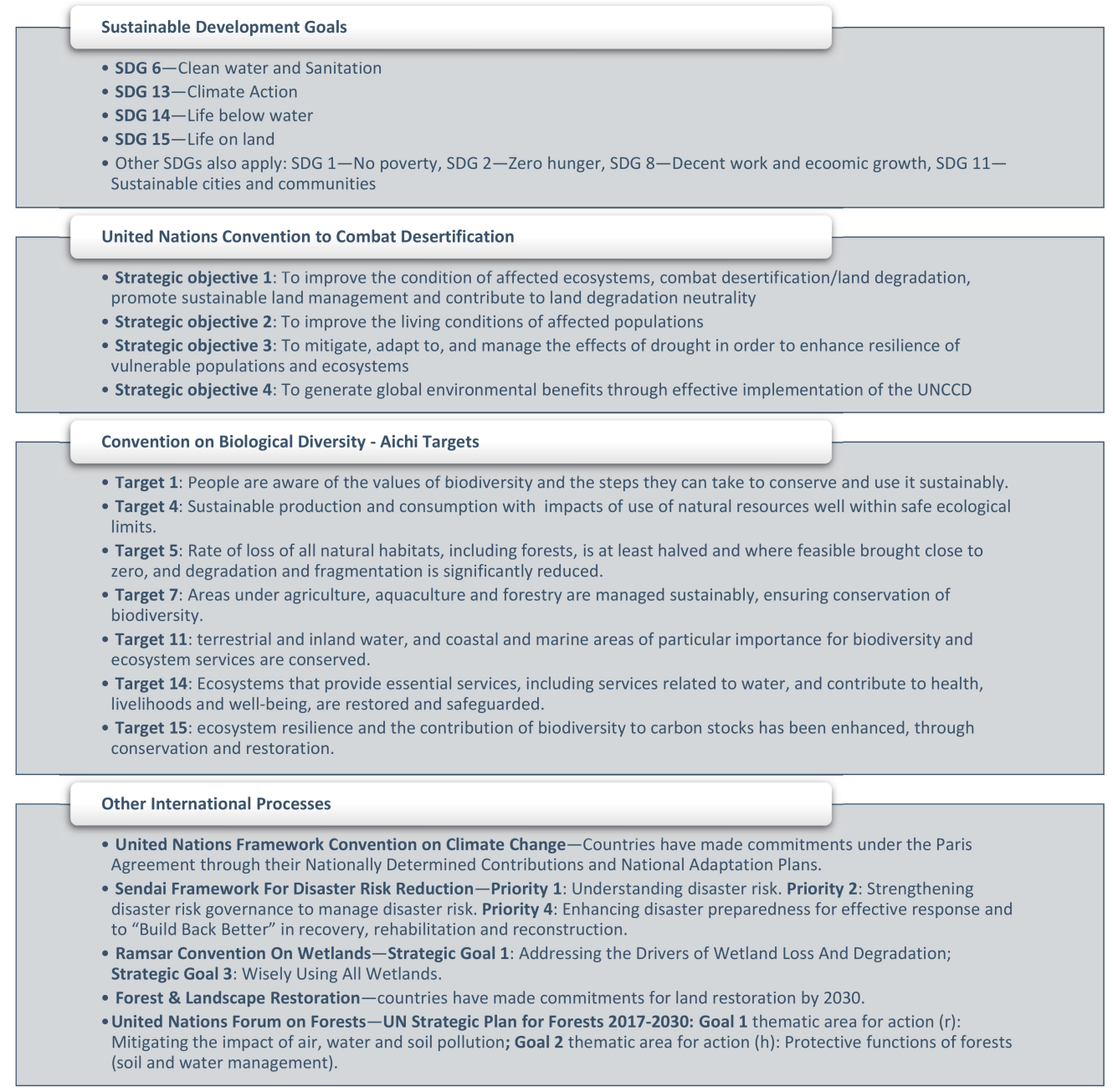

Figure 6. Relevant international political agenda/frameworks to the forest-water nexus.

This ongoing advocacy has resulted in explicit references to forest-water linkages in the SDGs, (I)NDCs and other international agenda. While further analysis at national and sub-national scales would be needed for the data presented in this paper, it does reveal interesting trends and key messages that could be leveraged to further influence international agenda and support the push for more integrated approaches to addressing global development issues and take advantage of the current momentum.

\subsubsection{Sustainable Development Goals}

When considering the SDGs, it is important to look at how these targets are measured and monitored to understand how the political momentum of the SDGs may be translated into actions 
relevant for the forest-water nexus. The indicators establish the benchmarks and determine how countries will report their progress. The current indicators for targets 6.6 and 15.1 are classified as Tier I, which according to the Interagency and expert group on SDG indicators are " ... conceptually clear, has an internationally established methodology and standards are available, and data are regularly produced by countries for at least 50 per cent of countries and of the population in every region where the indicator is relevant" [15]. This is important to note as data on these indicators highly depends on national reporting, validation and processes. The fact that these indicators are Tier 1 speaks of the political willingness at the national level to align or mainstream SDGs 6 and 15 into their policies and planning. To put this into perspective, as of 22 May 2019, over 122 indicators were still classified as Tier 2 or 3 and only 104 indicators had achieved Tier 1 status [15]. This further highlights the varying levels of political commitment for different SDGs, their targets and indicators as expressed in the UN Secretary General's report on the progress towards the SDGs [26].

The analysis of the methodologies for the relevant indicators highlighted possible areas of action. The UN Environment methodology depends on earth observation data on spatial extent and some water quality parameters analyzed by specialized agencies and relies on countries for the verification of data and local measurements of water quality [15]. This methodology limits its definition of water-related ecosystem to five categories: (1) vegetated wetlands, (2) rivers and estuaries, (3) lakes, (4) aquifers and (5) artificial waterbodies [27], for which only two types of forests are included because they are inundated with water either permanently or seasonally: swamp forests and mangroves. Some of the limitations of this methodology relate to the heavy reliance on external inputs and support form specialized agencies, as the methodology to generate the data is technical in nature. Ensuring proper analysis and validation from countries may be a challenge in terms of capacity and resources. Furthermore, limiting the definition of other water-related ecosystems to vegetated wetlands neglects the role that other ecosystems, especially forests, play in providing water-related ecosystem services. At a minimum, other forest types with strong associations to water services, such as cloud, riparian, peat and dryland forests should also be considered.

The Ramsar Convention methodology relies on information provided by the countries and has been embedded in the reporting mechanism of the Convention. Parties to the Convention decided that they would include information on the extent of wetlands in their territories in their national reports for the Ramsar COP13 and thereafter, highlighting the importance of this SDG to them. According to the metadata, parties will report on the total area of wetlands for the following Ramsar categories: marine/coastal, inland and human made. If available, countries also agreed to provide data on the percent change in the extent of wetlands over the last three years or more. By doing this, the countries created an intergovernmental mechanism to submit verified information based on their national wetland inventories. It is important to note that the guidelines provided by the Ramsar Convention apply to all wetlands (according to the Ramsar definition) irrespective of their status as a Wetland of International Importance or Ramsar site. In relation to the forest-water nexus, the Ramsar definition may include a number of forested water-related ecosystems. The Convention text indicates that wetlands include "... areas of marsh, fen, peatland or water, whether natural or artificial, permanent or temporary, with water that is static or flowing, fresh, brackish or salt, including areas of marine water the depth of which at low tide does not exceed six metres". It also states that wetlands "may incorporate riparian and coastal zones adjacent to the wetlands, and islands or bodies of marine water deeper than six metres at low tide lying within the wetlands" [15].

A closer look at the Ramsar wetlands classification shows that the following forested wetlands are taken into account into the three broad categories: freshwater tree-dominated wetlands (includes freshwater swamp forests, seasonally flooded forests and wooded swamps on inorganic soils), forested peatlands and intertidal forested wetlands (includes mangroves, nipah swamps and tidal freshwater swamp forests). Under this methodology, data will come from national wetlands inventories. However, some of the limitations include countries having their own methodologies for their wetlands inventories and inventories that may not be up to date. This classification, like the UN Environment 
classification, does not explicitly take into account other types of forests such as cloud forests or dryland forests. The limited scope of ecosystems in 6.6.1 is partly due to the expectation that the "other" water-related ecosystems will be covered by other SDGs and indicators [14,28], which is not the case. Moreover, while (some) ecosystems are measured, their effectiveness of providing water ecosystem services are not.

Yet, it is interesting and important to mention that this gap in the tier I indicators, could be addressed with other existing indicators and methodologies. For example, FRA has an indicator that reports on extent area forests managed with soil and/or water protection as an objective, as discussed previously. Although there are limitations to this data, namely its reliance on self-reporting and focus on extent area, it does address the interlinkages of forests and water ecosystem services better than the current SDG indicator methodology. The next FRA will be available in 2020, and is expected to launch an updated reporting system that includes remote sensing data. This could mean some of the issues raised here may be addressed in the near future.

\subsubsection{Forests and Water in Climate Change}

A review of nine (I)NDC synthesis reports focusing on either forests or water, revealed that the sustainable management both of these resources are important to address climate change, but synthesis reports on forests do not generally reference water, and vice versa; in general, the sectors are referenced separately [29]. For example, the Intended Nationally Determined Contributions ((I)NDCs) have been reviewed for references to land-use, land-use change and forestry (LULUCF) [30] and water [31]. At the time of the publication of the various reviews, 88 percent of (I)NDCs referenced forests [30] and 77 percent referenced water [31]. While these reviews hailed the (I)NDCs for recognizing the importance of LULUCF and water to address climate change, they also acknowledged that the proposed measures varied widely; most did not provide concrete, measurable targets or details on implementation; and most require financing commitments [30,32-34]. Additionally, these reviews were limited in scope, focusing their analysis from either a land or water management perspective; there was acknowledgement that forestry and water link to other sectors, but the reviews did not analyze the extent to which there were interlinkages, which is why an analysis on the forest-water nexus was performed.

Based on the analysis presented here, it is promising that the forest-water nexus receives substantial recognition within the (I)NDCs. By referencing the forest-water nexus, these countries have expressed a certain amount of political will towards integrated approaches and should be prioritized in strategic efforts to develop capacity and address potential gaps. Moreover, the acknowledgement of the forest-water nexus provides justification to engage with potential collaborators and donors, as well as to leverage financial support. Considering the status of forests managed for soil and water protection in the global south is low (based on FRA data), it is interesting that the recognition of the forest-water nexus in the (I)NDCs is not only high but relatively consistent in these regions. The climate change agenda, therefore, provides a promising entry point for address integrated forest-water management in developing countries.

With such a broad spectrum of proposed measures without finance-based commitments, and limited detail on what is expected to be achieved and how, the (I)NDCs, like the SDGs, appear to be an important step in the right direction for a process that needs to overcome major hurdles. In particular, it is well-known that institutional responsibility over forest and water resources are often different, which brings challenges to implementing an integrated approach to management and policy. Without providing details on how these sectoral silos will be better integrated, it is currently hard to assess how effective or realistic the (I)NDCs will be. As the (I)NDCs will be re-published in 2020, it will be interesting to review them again and to see how they have changed, and whether they include more concrete measures, including targets and financial commitments. Of course, having appropriate indicators and methodologies to measure and report progress would support countries in deciding 
their commitments and targets, as well as to strategize effective implementation, avoid the duplication of efforts and ease reporting commitments.

\subsubsection{Further International Momentum Required}

As the results of global efforts to implement the current international environmental agenda become available, the need to further consider the forest-water nexus in management strategies at different levels of governance becomes more evident. For example, the recent Intergovernmental Science-Policy Platform on Biodiversity and Ecosystem Services (IPBES) Global Assessment Report on Biodiversity and Ecosystem Services [35], which is the most up-to-date report providing progress on Aichi Targets, the SDGs and 10 other environmental agreements, shows that nature, ecosystem functions and services are directly related to the achievement of Sustainable Development Goals (SDGs) $1,2,3,6,11,13,14$ and 15. However, the report shows that the status and trends of ecosystems and their functions and services are negative, and that these trends provide evidence of poor, declining or partial contributions to achieving targets under the above-mentioned goals. This is concerning as many of these goals have been identified as key areas where an upward trend in management of forests for water ecosystem services could significantly contribute to achieving the targets. The alarming results of the report provide a strong argument to increase the area of forests managed for water ecosystem services. To do so, increasing awareness and consideration of the forest-water nexus within international frameworks is of utmost importance to ensure global implementation.

However, focusing on the international agenda and the inclusion of the forest-water nexus has its limitations as it can only infer success of advocacy and awareness at a high political level until national level reporting is completed. To better understand whether the forest-water nexus is taken into consideration, national and sub-national actions on the ground, including management and policies need to be considered.

\subsection{Big Picture (Global) Data Is Needed}

The fact that the forest-water nexus is based on context-specific relationships is a challenge for policymakers: without broadly applicable principles as a foundation, it is not likely that policies encouraging integrated approaches will be implemented. Although there are large information gaps and assumptions, national and global datasets may at least provide a sufficient 'big picture' to peak the interests of policymakers. For example, the FRA data previously presented provides a useful global picture by country and could create an impetus to investigate where forests for water are managed are located, whether they meet this objective and how effectively they contribute to national water goals.

Similarly, WRI Global Forest Watch Water data was used as it is one of the only mapping tools linking tree cover to water at a global scale. While there are limitations to the use of Hansen et al. (2013) [9] tree cover data, such as poor representation of dryland forest and trees outside forests [23], as well as assumptions regarding the relationships between tree cover and water risk, it provides a useful global scale picture of forests and water. The consistent trend that tree cover loss may influence erosion, base water stress and forest fire risk, irrespective of forest and soil type, needs further validation. However, it does support the notion that tree cover loss, as part of a larger land conversion process, may contribute to higher water-related hazards due to changes in soil properties and hydrological patterns [1,2].

Such global data provide an interesting narrative for high-level decision-makers engaged in the negotiations of international agenda and national-level commitments. Moreover, the data provides a rough baseline that could be used to initiate research where there are forest-water knowledge gaps, such as certain geographic areas, biomes or in response to socio-political questions.

\section{Conclusions}

While sustainable forest management, in principle, takes water ecosystem services into account, global awareness and knowledge of forest-water relationships is generally limited, and primarily 
rests within the scientific community. Though steps have been made to increase the recognition of forest-water interlinkages in policy and practice, strides are needed to break down the silos and ensure an integrated approach with greater collaboration between science and policy where research is guided by the interests and questions of policymakers. In order to facilitate this process, research on the forest-water nexus needs to move beyond the bio-physical and include the socio-political. Future research should focus on addressing major research gaps in forest-water policy and governance, as well as potential socio-economic and political impacts. As reporting for SDG indicators 6.6.1 and 15.1.1 takes place in 2020, an assessment of the data submitted by countries should be done and added to the findings of this study. Together, these will contribute to efficiently and effectively harness the current momentum in the international environmental arena and increase the political support for better management of forests for water-related ecosystem services.

The analysis of available global data provided in this paper indicates a growing understanding of the importance of forest-water relationships, as well as the political will to address it. Moreover, the sustainable development and climate change agendas (and other international policy frameworks) may provide the impetus and financing to address cross-sectoral issues in a comprehensive and strategic way. Similarly, the growing emphasis on restoration, including the UN Decade on Ecosystem Restoration, provides incentive to better understand how large-scale land cover and land-use will affect water. However, as shown by this study, there is no single reporting mechanism that allows us to better understand the extent to which forests provide water ecosystem services, nor their management and/or management effectiveness.

Due to the lack of an indicator that specifically addresses forest-water interactions in the current international frameworks, the methodology hereby presented allows for a robust global analysis and provides a baseline for recommendations and further research. This is particularly useful, especially with upcoming revisions of the (I)NDCs and reports for the relevant SDGs. Furthermore, the research presented in this paper could be used to inform the SDG monitoring process so it includes reporting on the state, extent, management and management effectiveness of more forest-water ecosystems. Especially as this process has to be constantly reviewed as mandated by the General Assembly of the United Nations through resolution A/RES/71/313 [36], providing a good opportunity for better and improved methodologies to be used.

Author Contributions: Conceptualization, E.S.; methodology, E.S.; formal analysis, E.S., S.J. and V.V.B.; data curation, E.S., S.J. and V.V.B.; writing—original draft preparation, all authors; writing-review and editing, all authors; visualization, all authors.

Funding: This research received no external funding.

Acknowledgments: The authors acknowledge the support of Ewald Rametsteiner, Deputy Director-Forestry Department, FAO, Rome, Italy.

Conflicts of Interest: The authors declare no conflict of interest. The views expressed in this publication are those of the author(s) and do not necessarily reflect the views or policies of the Food and Agriculture Organization of the United Nations.

\section{Appendix A}

Definitions:

Adaptation-adaptation to climate change refers to adjustment in natural or human systems in response to actual or expected climatic stimuli or their effects, which moderates harm or exploits beneficial opportunities. Various types of adaptation can be distinguished, including anticipatory and reactive adaptation, private and public adaptation, and autonomous and planned adaptation.

Baseline Water Stress-baseline water stress measures total annual water withdrawals expressed as a percent of the total annual available flow.

Ecosystem Services-the benefits people obtain from ecosystems, classified into provisioning, regulating, cultural and supporting services.

Ecosystem Services for Mitigation/Adaptation 
Erosion Risk-probability rate for an erosion process to start and develop as a result of changes of one or several erosion inducing or controlling factors.

FAO region-FAO subdivides its work into five regions: region of Africa, region of Latin America and Caribbean, region of Near East and North Africa, region of Europe and Central Asia and region of Asia and the Pacific. It has regional offices in each of these regions for overall identification, planning and implementation of FAO's priority activities in the region

Integrated (water) resource management-the process that promotes the coordinated development and management of water, land and related resources in order to maximize economic and social welfare in an equitable manner without compromising the sustainability of vital ecosystems and the environment

(I)NDC-(Intended) Nationally Determined Contributions) identifying post-2020 national climate targets including mitigation and adaptation actions that countries commit to. The voluntary INDCs become binding (NDC) once a country ratifies the Paris Agreement

Mangrove-area of forest and other wooded land with mangrove vegetation

Mitigation-in the context of climate change, a human intervention to reduce the sources or enhance the sinks of greenhouse gases.

Rainforest-an evergreen forest associated with a climate characterized by continual high humidity and abundant rainfall ( $>60$ in or $>1524 \mathrm{~mm}$ per year) and a short or no dry season.

Riparian Forest-vegetation directly adjacent to rivers and streams

Swamp forest-natural forests with $>30 \%$ canopy cover, below $1200 \mathrm{~m}$ altitude, composed of trees with any mixture of leaf type and seasonality, but in which the predominant environmental characteristic is a waterlogged soil.

Tree loss-tree cover loss refers to the removal of trees

Wetland-wetlands are areas of marsh, fen, peatland or water, whether natural or artificial, permanent or temporary, with water that is static or flowing, fresh, brackish or salt, including areas of marine water the depth of which at low tide does not exceed six meters.

\section{References}

1. Ellison, D.; Morris, C.E.; Locatelli, B.; Sheil, D.; Cohen, J.; Murdiyarso, D.; Gutierrez, V.; van Noordwijk, M.; Creed, I.; Pokorny, J.; et al. Trees, forests and water: Cool insights for a hot world. Glob. Environ. Chang. 2017, 43, 51-61. [CrossRef]

2. Creed, I.F.; van Noordwijk, M. Forest and Water on a Changing Planet: Vulnerability, Adaptation and Governance Opportunities: A Global Assessment Report; International Union of Forest Research Organizations: Austria, Vienna, 2018.

3. MEA (Millenium Ecosystem Assessment). Global Assessment Report; Island Press: Washington, DC, USA, 2005.

4. Springgay, E.; Dalton, J.; Samuelson, L.; Bernard, A.; Buck, A.; Cassin, J.; Matthews, N.; Matthews, J.; Tengberg, A.; Bourgeois, J.; et al. Championing the Forest-Water Nexus. Report on the Meeting of Key Forest and Water Stakeholders; SIWI: Stockholm, Sweden, 2018.

5. WRI (World Resource Institute). Global forest water watch. Available online: https://www.globalforestwatch. org/ (accessed on 27 May 2019).

6. FAO (Food and Agricultural Organization). Global Forest Resources Assessment 2015: How Are the World's Forests Changing, 2nd ed.; Food and Agricultural Organization: Rome, Italy, 2015.

7. UNFCCC NDC Registry. Available online: https://www4.unfccc.int/sites/NDCStaging/Pages/All.aspx (accessed on 31 May 2019).

8. (I)NDC Submission Portal. Available online: https://www4.unfccc.int/sites/submissions/indc/Submission\% 20Pages/submissions.aspx (accessed on 31 May 2019).

9. Hansen, M.C.; Potapov, P.V.; Moore, R.; Hancher, M.; Turubanova, S.A.; Tyukavina, A.; Thau, D.; Stehman, S.V.; Goetz, S.J.; Loveland, T.R.; et al. High-resolution global maps of 21st-century forest cover change. Science 2013, 342, 850-853. [CrossRef] [PubMed]

10. FAO (Food and Agriculture Organization). World Map of the Major Hydrological Basins (Derived From HydroSHEDS); Food and Agriculture Organization: Rome, Italy, 2011. 
11. Qin, Y.; Gartner, T.; Minnemeyer, S.; Reig, P.; Sargent, S. Global Forest Watch Water Metadata Document. Technical Note; World Resources Institute: Washington, DC, USA, 2016.

12. Renard, K.G.; Foster, G.R.; Weesies, G.A.; McCool, D.K.; Yoder, D.C. Predicting soil erosion by water: A guide to conservation planning with the Revised Universal Soil Loss Equation (RUSLE). In Agriculture Handbook; U.S. Department of Agriculture: Washington, DC, USA, 1997.

13. Hofste, R.W.; Kuzma, S.; Walker, S.; Sutanudjaja, E.H.; Bierkens, M.F.P.; Kujiper, M.J.M.; Sanchez, M.F.; van Beek, R.; Wada, Y.; Rodríguez, S.G.; et al. Aqueduct 3.0: Updated Decision-Relevant Global Water Risk Indicators; World Resources Institute: Washington, DC, USA, 2019; Technical Note.

14. FAO (Food and Agricultural Organization). The State of the World's Forests 2018-Forest Pathways to Sustainable Development; Food and Agricultural Organization: Rome, Italy, 2018.

15. UNSTATS (United Nations Statistics Division). Tier Classification for Global SDG Indicators; United Nations Statistics Division: New York, NY, USA, 2019. Available online: https://unstats.un.org/sdgs/files/Tier Classification_of_SDG_Indicators_22_May_2019_web.pdf (accessed on 1 July 2019).

16. UNECE/FAO (United Nations Economic Commission for Europe/Food and Agriculture Organization). Forests and Water: Valuation and Payments for Forest Ecosystem Services; United Nations Economic Commission for Europe/Food and Agriculture Organization: Geneva, Switzerland, 2018.

17. Bruijnzeel, L.A. Hydrological functions of tropical forests: Not seeing the soil for the trees? Agric. Ecosyst. Environ. 2014, 104, 185-228. [CrossRef]

18. United States Forestry Service. Water, Air, and Soil. Available online: https://www.fs.fed.us/sciencetechnology/water-air-soil (accessed on 27 May 2019).

19. UNU (United Nations University Institute for Water, Environment \& Health). Water Security E the Global Water Agenda. A UN-Water Analytical Brief; United Nations University Institute for Water, Environment \& Health: Hamilton, ON, Canada, 2013.

20. 2030 Water Resources Group. Charting Our Water Future: Economic Frameworks to Inform Decision-Making; 2030 WRG: Washington, DC, USA, 2009.

21. WWAP (United Nations World Water Assessment Programme). The United Nations World Water Development Report 2015: Water for a Sustainable World; UNESCO: Paris, France, 2015.

22. Mekonnen, M.M.; Hoekstra, A. Four billion people facing severe water scarcity. Sci. Adv. 2016, 2, 1-6. [CrossRef] [PubMed]

23. Bastin, J.F.; Finegold, Y.; Garcia, C.; Mollicone, D.; Rezende, M.; Routh, D.; Zohner, CM.; Crowther, T.W. The extent of forest in dryland biomes. Science 2017, 356, 635-638. [CrossRef] [PubMed]

24. FAO (Food and Agricultural Organization). Forests and Water: International Momentum and Action; Food and Agricultural Organization: Rome, Italy, 2013.

25. SIWI (Stockholm International Water Institute). Water: The Path to Agenda 2030 Implementation; Stockholm International Water Institute: Stockholm, Sweden, 2018; Available online: https:/www.siwi.org/wp-content/ uploads/2018/06/Water-the-path-to-Agenda-2030-implementation_WEB.pdf (accessed on 28 May 2019).

26. ECOSOC (United Nations Economic and Social Council). Special Edition: Progress towards the Sustainable Development Goals. Report of the Secretary-General; United Nations Economic and Social Council: New York, NY, USA, 2019; Available online: https:/unstats.un.org/sdgs/files/report/2019/secretary-general-sdg-report2019--EN.pdf (accessed on 13 September 2019).

27. UN Environment. Progress on Water-related Ecosystems-Piloting the Monitoring Methodology and Initial Findings for SDG Indicator 6.6.1; UN Environment: Geneva, Switzerland, 2018; Available online: http: //www.unwater.org/app/uploads/2018/08/661-progress-on-water-related-ecosystems-2018.pdf (accessed on 11 September 2019).

28. UN-Water. Integrated Monitoring Guide for Sustainable Development Goal 6 on Water and Sanitation: Targets and Global Indicators; UN Environment: Geneva, Switzerland, 2017; Available online: https://www.unwater.org/ app/uploads/2017/10/G2_Targets-and-global-indicators_Version-2017-07-14.pdf (accessed on 11 September 2019).

29. Gustafsson, M. The Forest-Water Nexus in (I)NDC Reviews-identifying Good Examples and Gaps to Address; Stockholm International Water Institute: Stockholm, Sweden, 2019; Unpublished work.

30. FAO (Food and Agricultural Organization). The Agriculture Sectors in the Intended Nationally Determined Contributions: Analysis. Environment and Natural Resources Management Working Paper No. 62; Food and Agricultural Organization: Rome, Italy, 2016. 
31. French Water Partnership and Coalition Eau. Review of the Integration of Water within the Intended Nationally Determined Contributions (INDCs) for COP21. 2016. Available online: http://www.coalition-eau. org/wpcontent/uploads/2016-03-review-of-water-integration-in-indc-vf.pdf (accessed on 30 May 2019).

32. WWF (World Wildlife Fund). INDC Analysis: An Overview of the Forest Sector. 2015. Available online: http://wwf.panda.org/wwf_news/?257883/INDC-Analysis-An-Overview-of-the-Forest-Sector (accessed on 30 May 2019).

33. GIZ (Deutsche Gesellschaft für Internationale Zusammenarbeit). Sectoral Implementation of Nationally Determined Contributions (NDCs). 2017. Available online: https://www.transparency-partnership.net/sites/ default/files/u2618/giz2017-en-ndcs-sectoralimplementation-forestry.pdf (accessed on 30 May 2019).

34. IUCN (International Union for Conservation of Nature). Forest Landscape Restoration: Unlocking the Mitigation and Adaptation Potential of the Forest and Land Sector, IUCN Brief. No. 21; IUCN: Gland, Switzerland, 2017; Available online: https://www.iucn.org/sites/dev/files/content/documents/20171107_iucn_forest_brief_21.pdf (accessed on 30 May 2019).

35. IPBES (Intergovernmental Science-Policy Platform on Biodiversity and Ecosystem Services). Report of the Plenary of the Intergovernmental Science-Policy Platform on Biodiversity and Ecosystem Services on the Work of Its Seventh Session; Intergovernmental Science-Policy Platform on Biodiversity and Ecosystem Services: Bonn, Germany, 2019; Available online: www.ipbes.net/system/tdf/ipbes_7_10_add-1__advance_0.pdf?file=1\& type $=$ node\&id $=35245$ (accessed on 31 May 2019).

36. General Assembly of the United Nations. Resolution Adopted by the General Assembly on 6 July 2017 (Res/71/313). 2017. Available online: https://undocs.org/A/RES/71/313 (accessed on 1 July 2019).

(C) Food and Agriculture Organization of the United Nations, 2019. Licensee MDPI, Basel, Switzerland. This article is an open access article distributed under the terms and conditions of the Creative Commons Attribution (CC BY) license (http://creativecommons.org/licenses/by/4.0/). 